\title{
A Study on Neutrophil Lymphocyte Ratio in Covid 19 Patients in Tertiary Care Centre
}

\author{
Celine $^{1}$, T.N. Vijayalakshmi ${ }^{2}$, G. Chandini ${ }^{3}$ \\ ${ }^{1}$ Professor \& Head, ${ }^{2}$ Associate Professor, ${ }^{3} I I I$ year Postgraduate, Department of Physiology, Chengalpattu Medical \\ College, Chengalpattu, Tamil Nadu, India
}

\begin{abstract}
Introduction: COVID-19 pandemic is spread by droplet infectionwith symptoms of fever, cough, diarrhea,dyspnea, fatigue, myalgia, headache, anosmia and ageusia. Morbidity and mortality is higher among elderly and in patients with comorbidities especially Diabetes Mellitus(DM). Biomarkers of inflammation are potential predictors for prognosis in covid patients.
\end{abstract}

Aim: To analyze the association of NLR in covid 19 patients with symptoms and diabetic status Objective: 1. To studyNLR in covid 19 patients with and without symptoms

2. To study the association of NLR between diabetic and non-diabetic covid 19 patients.

3. To study the association between symptomatology and NLR in diabeticcovid 19 patients.

Methodology: 3000 RT-PCR confirmed Covid 19 patients who attended triage op were included afterEthics committee approval.Patients were grouped as patients with and without symptoms and patients with and without DM.The diabetic Covid patients were also analyzed based on the symptoms. Blood samples onreporting were used for analysis of NLR andparameters analyzed using SPSS23.0 version.

Result: There is no statistically significant difference in NLR among Covid symptomatic and asymptomatic patients. But NLR is markedly raised in covid symptomatic patients with diabetes mellitus.

Key Words: COVID 19, Diabetes Mellitus, Neutrophil Lymphocyte Ratio

\section{Introduction}

The new coronavirus disease 2019 (COVID-19), caused by severe acute respiratory syndrome coronavirus 2 (SARS-CoV-2), is a highly communicable infectious disease.WHOdeclared it as a pandemic in March 2020 and current evidences suggestthat SARS-CoV-2

\section{Corresponding author:}

\section{Dr. G. Chandini}

Final Year Post Graduate, MD Physiology

Department of Physiology, Chengalpattu Medical

College and Hospital

Email id - chandinig90@gmail.com spreads among people via direct contactroutes and by droplet, airborne and, fomite transmission. ${ }^{(1,2)}$. The common clinical features of COVID-19 include fever, dry cough, dyspnea, fatigue, myalgia, headache, anosmia, ageusia and diarrhea ${ }^{(3,4)}$. Patients with severe disease, may develop life threatening complications like, acute respiratory distress syndrome (ARDS), metabolic acidosis, coagulopathy, and septic shock ${ }^{(5)}$. The pathophysiology of complications in Covid 19 patients is under study and new theories are still evolving. One of the proposed mechanisms of complications in Covid infection is Cytokine storm. Cytokine storm syndrome can be triggered by direct target cell lysis with release of cytokines like interferon 
gamma (IFN- $\gamma$ ) or tumour necrosis factor alpha (TNF- $\alpha)$ or by activation of $\mathrm{T}$ cells with subsequent cytokine release $^{(6)}$. These cytokines cause activation of innate immune cells like macrophages and endothelial cells with further cytokine release ${ }^{(7)}$. Inflammation, plays a key role in progression of COVID-19 pneumonitis and vasculitis. InCOVID-19 patients leukocyte count in the peripheral blood is normal ordecreased with reduced lymphocyte count in the earlystage.Neutrophils are the major constituent of leukocytes and are responsible for first line of defense against pathogens, whereas lymphocytes are regulatory and protective component of immune system ${ }^{(8,9)}$. However,Systemicinflammation destroys CD4+ $\mathrm{T}$ lymphocytes and increases suppressor CD8+ T lymphocytes, thereby resulting in an increased neutrophil-to-lymphocyte ratio (NLR), NLR has been universally accepted as an inflammatory marker ${ }^{(10,11)}$. In a study conducted byYang et al., NLR was found to be an independent prognostic factor in patients with COVID-19. This reinforces the belief in the relationship between hyper-inflammation and SARS-CoV-2.

Studies conducted by Zhuo F et al, have suggested that, Covid infection and its severity is higher amongst individuals with comorbidities, especially those with diabetes mellitus ${ }^{(12)}$.Diabetics reportedfor $12 \%-22 \%$ of patients with COVID-19, higher thanthe incidence in non-diabetic people $9.3 \%{ }^{(13)}$. Diabetes, itself being a chronic inflammatory disease, presents with significantly higher incidence of mortality and multiple organ damages..$^{(14)(15)}$.

Identifying early warning signs of covid 19 infection and providing treatment at the right time, helps in reducing the mortality and shorten the hospital stay with better cure rate. Various blood parameters showing immune status of human, have been identified as potential markers in assessing the severity of the disease. But these tests are mostly expensive and time consuming, which challenges the process of early identification and initiation of treatment. In such a case, Complete Blood Count and arriving at NLR is a specific and sensitive indicator of immune status, which is inexpensive with less turnaround time ${ }^{(16)}$. Hence this study was undertaken to find the association of NLR among symptomatic and diabetic patients in patients attending triage op where patients are segregated for different treatment modalities.

AIM: To analyze the association of NLR in covid 19 patients with symptoms and diabetic status

Objective:

1. To study neutrophil lymphocyte ratio in covid 19 patients with and without symptoms

2. To study association of NLR between diabetic and non-diabetic patients of covid 19.

3. To study the association between symptomatology and neutrophil lymphocyte ratio in diabetic patients of covid 19.

Methodology: The demographic, clinical and laboratory characteristics of RT-PCR confirmed, 3000Covid -19 patients who attended Triage OPD at Chengalpattu Medical college \& Hospitalfor a period of one monthwas collectedafter approval from Institutional ethics committee.

Inclusion Criteria: COVID 19 patients of age group 18 to 70 years of both genders

Exclusion criteria: COVID 19 positive pediatric cases, antenatal and postnatal mothers,post-operative cases and sick cases admitted in COVID ICU

Symptoms of COVID 19 such as fever, cough, sore throat, myalgia, diarrhea, anosmia were noted. Comorbidities such as Type 2 Diabetes Mellitus, Hypertension, Coronary Artery Disease, Bronchial asthma, Tuberculosis, Epilepsy, Chronic Kidney Disease on Dialysis and other medical conditions documented were noted. NLR on reporting to triage was noted from Complete Blood Count measured by Automated Sysmex Analyzer.

The patients were clinically categorized from the received data as

1. Patients with symptoms 
2. Patients without symptoms

3. Patients with Diabetes Mellitus

- Further subdivided as, symptomatic and asymptomatic

.The parameters were analyzed using SPSS 21.0 version.

\section{Results}

Results were analyzed by Descriptive statistics, ' $t$ ' test, $\mathrm{p}$ value $<0.05$ was considered significant.

Table No: 1- Comparison of NLR in Covid patients with and without symptoms

\begin{tabular}{|c|c|c|c|}
\hline S.no & $\begin{array}{c}\text { Covid patients } \\
\text { Total(n=3000) }\end{array}$ & $\begin{array}{c}\text { NLR } \\
\text { Mean } \pm \text { SD }\end{array}$ & p value \\
\hline 1. & $\begin{array}{c}\text { Covid patients with symptoms } \\
(\mathrm{n}=620)\end{array}$ & $2.309 \pm 1.68$ & 0.09 \\
\hline 2. & $\begin{array}{c}\text { Covid patients without symptoms } \\
(\mathrm{n}=2380)\end{array}$ & $2.06 \pm 1.56$ & \\
\hline
\end{tabular}

Table No: 2- Comparison of NLR in Covid patients with and without Diabetes mellitus

\begin{tabular}{|c|c|c|c|}
\hline S.no & $\begin{array}{c}\text { Covid patients } \\
\text { Total(n=3000) }\end{array}$ & $\begin{array}{c}\text { NLR } \\
\text { Mean } \pm \text { SD }\end{array}$ & p value \\
\hline 1. & $\begin{array}{c}\text { Covid with Diabetes mellitus } \\
(\mathrm{n}=350)\end{array}$ & $4.45 \pm 2.3$ & 0.00004 \\
\hline 2. & $\begin{array}{c}\text { Covid without Diabetes mellitus } \\
(\mathrm{n}=2650)\end{array}$ & $2.02 \pm 1.2$ & \\
\hline
\end{tabular}

Table No: 3- Comparison of NLR among Diabetic Covid patients with and without symptoms

\begin{tabular}{|c|c|c|c|}
\hline S.no & $\begin{array}{c}\text { Covid patients with Diabetes mellitus } \\
\text { Total(n=350) }\end{array}$ & $\begin{array}{c}\text { NLR } \\
\text { Mean } \pm \text { SD }\end{array}$ & p value \\
\hline \multirow{2}{*}{1.} & $\begin{array}{c}\text { Diabetic patients with symptoms } \\
(\mathrm{n}=132)\end{array}$ & $4.93 \pm 2.56$ & 0.00012 \\
\hline 2. & $\begin{array}{c}\text { Diabetic patients without symptoms } \\
(\mathrm{n}=218)\end{array}$ & $3.19 \pm 1.049$ & \\
\hline
\end{tabular}




\section{Discussion}

In our study, out of 3000 Covid patients, 620 were symptomatic. On analysing the NLR values among symptomatic and asymptomatic patients, table- 1 shows, there was a mild increase in NLR among symptomatic patients $(2.309 \pm 1.68)$, compared to asymptomatic patients $(2.06 \pm 1.56)$, which was not statistically significant. However, the NLR in symptomatic patient was in higher limit of normal range.This is consistent with study conducted by Jumana Mansur Aljishi et al in Saudi arabia on symptomatic and asymptomatic covid patients. ${ }^{(17)}$ According to Al-Tawfiq et al, and Graselli $\mathrm{G}$ et alit was foundthat elevated NLR was significantly associated with illnessseverity, taking into consideration the presence of comorbidities. ${ }^{(18)(19)}$

Among 3000 Covid patients, 350 had Diabetes mellitus. On analyzing their NLR, from table-2, we found that it is significantly higher with a mean value of 4.45 \pm 2.3 , than that of the covid patients without diabetes mellitus, $2.02 \pm 1.2$. This is consistent with study done by Anurag et al, in Jharkand. ${ }^{(1)}$. Richardson et al, stated that the most common comorbidity associated with Covid -19 is Diabetes mellitus. ${ }^{(20)}$. Studies conducted by Samaras K et al, Marioni et al, showed that Diabetes mellitus is associated with low grade chronic systemic inflammation, presenting with increased inflammatory mediators. ${ }^{(21-23)}$ Various studies conducted by Shiny A et al, Sefil $\mathrm{F}$ et al and Luo $\mathrm{M}$ et al, have reported that increased NLR in diabetics is linked with poor glycemic control, insulin resistance and cardiovascular events. $(24,25)(26,27)$

Table-3 shows, out of 350 diabetic Covid patients, 132 patients were symptomatic and 218 were asymptomatic. On analyzing NLR among them, it was elevated in symptomatic diabetes mellitus patients (4.93 \pm 2.56 ), compared to asymptomatic diabetic patients $(3.19 \pm 1.049)$, which was statistically significant. Guozhen li et al, conducted a retrospective study on clinical characteristics of diabetic patients with covid 19, showing that the patients with DM who landed up in severe category of Covid infection with moderate to severe symptoms, suffered from more complications, showing prominent lymphopenia with increased NLR, when compared with those diabetic covid patients without symptoms. ${ }^{(26,28)}$.

This increased NLR in diabetic Covid patients, has been documented in various studies. But our study shows that, the NLR is markedly increased in diabetic patients with symptoms, compared to asymptomatic diabetic patients, which is also statistically significant. This proves the fact that NLR, can be used as a screening tool, for early identification of high risk cases amongst Covid patients with diabetes.

Significance of NLR in Covid:In covid, viral antigens cause activation of cell mediated immunity and humoral immunity. There occurs a marked interaction withmolecules like vascular endothelial growth factor (VEGF), interleukin-6, interleukin-8, tumor necrosis factor-alpha, interferon-gamma, and granulocyte colonystimulating factor, resulting in profound inflammatory reactions and altered NLR.According to $\mathrm{Ji} P$ et al and Yang $\mathrm{X}$ et al, VEGF-A and VEGF-Care notorious contributors to inflammation in SARSCoV2 $2^{(29)(30)}$.In another study conducted by Ciccullo et al, an NLR of greater than four was seen as a predictor of theadmission of COVID-19 patients to the intensive care unit ${ }^{(31)}$

The potential mechanisms for increased NLR in diabetic Covid patients, is over-activated inflammation and imbalanced immune response in DM.

Diabetes is a condition related with proinflammatory stage, patients suffer from dysregulated immune response and were found to have altered cytokine profile, signifying the severity of Covid in them as reported in a study conducted by $\mathrm{Yang} \mathrm{J}$ et $\mathrm{al}^{(32,33)} \mathrm{A}$ recent clinical study conducted byGuo et al,reported thatcompared to COVID-19 patients without diabetes, peoplewith diabetes had activated inflammatory response ${ }^{(34)}$. Hyperglycemia wasan independent predictor of a high neutrophil count. In a study conducted by Lim S et al, it showed there were moderatepositive correlations between Fasting Blood Glucose levels and NLRin the critical group of Covid patients with DM. ${ }^{(35,36)}$ 
Mehta $\mathrm{N}$ et al showed that, use of thiazolidinediones in diabetics, increased the expression of ACE2 receptors, to which corona virus binds. ${ }^{(37)}$ This is reported in a study conducted by Gaoli Liu et al, on role of NLR in prognosis of type 2 diabetics with covid $19,{ }^{(2)}$

\section{Conclusion}

In our study there is no statistically significant difference in NLR among symptomatic and asymptomatic Covid patients. NLR is increased in diabetic covid patients when compared with Non-diabetic and is statistically significant.The increase in NLR is more in symptomatic Covid patients with DM than in asymptomatic diabetic patients showing the marked increase in inflammation and chances for complication.NLR is a simple tool, which can be estimated at ease, in a triage centre, to assess the immune status and inflammatory response. It also helps in early identification of sick cases, which is ideally done at a triage centre, to categorize the patients, especially in patients with Diabetes mellitus and to refer them promptly, without delay, for initiation of treatment.

Ethical Committee Clearance: Taken from Institutional Ethics Committee, chengalpattu medical college.

\section{Source of Funding: Self}

\section{Conflict of Interest: Nil}

\section{References}

1. Anurag A, Jha PK, Kumar A. Differential white blood cell count in the COVID-19: A crosssectional study of 148 patients. Diabetes Metab Syndr Clin Res Rev. 2020 Nov;14(6):2099-102.

2. Liu G, Zhang S, Hu H, Liu T, Huang J. The role of neutrophil-lymphocyte ratio and lymphocytemonocyte ratio in the prognosis of type 2 diabetics with COVID-19. Scott Med J. 2020 Nov;65(4):15460.

3. Analysis of Symptoms of COVID-19 Positive Patients and Potential Effec | OAEM [Internet]. [cited 2021 Jun 21]. Available from: https://www. dovepress.com/analysis-of-symptoms-of-covid19-positive-patients-and-potential-effec-peer-
reviewed-fulltext-article-OAEM

4. Retrospective Analysis of Clinical Features in 101 Death Cases with COVID-19 | medRxiv [Internet]. [cited 2021 Jun 21]. Available from: https://www.medrxiv.org/ content/10.1101/2020.03.09.20033068v2

5. Pimentel GD, Dela Vega MCM, Laviano A. High neutrophil to lymphocyte ratio as a prognostic marker in COVID-19 patients. Clin Nutr ESPEN. 2020 Dec;40:101-2.

6. Sanders JM, Monogue ML, Jodlowski TZ, Cutrell JB. Pharmacologic Treatments for Coronavirus Disease 2019 (COVID-19): A Review. JAMA [Internet]. 2020 Apr 13 [cited 2021 Jun 21]; Available from: https://jamanetwork.com/journals/ jama/fullarticle/2764727

7. Ye Q, Wang B, Mao J. The pathogenesis and treatment of the 'Cytokine Storm' in COVID-19. J Infect. 2020 Jun;80(6):607-13.

8. Buyukkaya E, Karakas MF, Karakas E, Akçay AB, Tanboga IH, Kurt M, et al. Correlation of neutrophil to lymphocyte ratio with the presence and severity of metabolic syndrome. Clin Appl Thromb Off J Int Acad Clin Appl Thromb. 2014 Mar;20(2):159-63.

9. Feng X, Li S, Sun Q, Zhu J, Chen B, Xiong M, et al. Immune-Inflammatory Parameters in COVID-19 Cases: A Systematic Review and Meta-Analysis. Front Med [Internet]. 2020 Jun 9 [cited 2021 Jun 21];7. Available from: https://www.ncbi.nlm.nih. gov/pmc/articles/PMC7295898/

10. 2019-issue-1-vijayalakshmi.pdf [Internet]. [cited 2021 Jun 25]. Available from: http://njp.org.in/ images/pdf/2019-issue-1-vijayalakshmi.pdf

11. Full article: Neutrophil-lymphocyte ratio as an important assessment tool [Internet]. [cited 2021 Jun 25]. Available from: https://www.tandfonline. com/doi/full/10.1586/14779072.2014.902309

12. Zhou F, Yu T, Du R, Fan G, Liu Y, Liu Z, et al. Clinical course and risk factors for mortality of adult inpatients with COVID-19 in Wuhan, China: a retrospective cohort study. The Lancet. 2020 Mar;395(10229):1054-62.

13. Dey RK, Hilmy AI, Imad HA, Yoosuf AA, Latheef AA. COVID-19 and emergencies in patients with diabetes: two case reports. J Med Case Reports. 
2021 Feb 2;15(1):57.

14. Sasirekha G, Celine D, Umayal CC, Viji D, Indumathi $\mathrm{M}$, Subathra $\mathrm{S}$, et al. Association Between Neutrophil Lymphocyte Ratio and Cognitive Function in Type II Diabetes Mellitus. Indian J Physiol Pharmacol. :6.

15. Fang L, Karakiulakis G, Roth M. Are patients with hypertension and diabetes mellitus at increased risk for COVID-19 infection? Lancet Respir Med. 2020 Apr;8(4):e21.

16. Imran MM, Ahmad U, Usman U, Ali M, Shaukat A, Gul N. Neutrophil/lymphocyte ratio-A marker of COVID $\square 19$ pneumonia severity. Int J Clin Pract [Internet]. 2021 Apr [cited 2021 Jun 18];75(4). Available from: https://onlinelibrary.wiley.com/ doi/10.1111/ijcp.13698

17. AlJishi JM, Alhajjaj AH, Alkhabbaz FL, AlAbduljabar TH, Alsaif A, Alsaif H, et al. Clinical characteristics of asymptomatic and symptomatic COVID-19 patients in the Eastern Province of Saudi Arabia. J Infect Public Health. 2021 Jan $1 ; 14(1): 6-11$.

18. Al-Tawfiq JA, Leonardi R, Fasoli G, Rigamonti D. Prevalence and fatality rates of COVID-19: What are the reasons for the wide variations worldwide? Travel Med Infect Dis. 2020;35:101711.

19. Grasselli G, Pesenti A, Cecconi M. Critical Care Utilization for the COVID-19 Outbreak in Lombardy, Italy: Early Experience and Forecast During an Emergency Response. JAMA. 2020 Apr 28;323(16):1545.

20. Richardson S, Hirsch JS, Narasimhan M, Crawford JM, McGinn T, Davidson KW, et al. Presenting Characteristics, Comorbidities, and Outcomes Among 5700 Patients Hospitalized With COVID-19 in the New York City Area. JAMA. 2020 May 26;323(20):2052.

21. Samaras K, Sachdev PS. Diabetes and the elderly brain: sweet memories? Ther Adv Endocrinol Metab. 2012 Dec 1;3(6):189-96.

22. Marioni RE, Strachan MWJ, Reynolds RM, Lowe GDO, Mitchell RJ, Fowkes FGR, et al. Association between raised inflammatory markers and cognitive decline in elderly people with type 2 diabetes: the Edinburgh Type 2 Diabetes Study. Diabetes. 2010
Mar;59(3):710-3.

23. The prognostic value of preoperative NLR, d-NLR, PLR and LMR for predicting clinical outcome in surgical colorectal cancer patients. - Abstract - Europe PMC [Internet]. [cited 2021 Jun 21]. Available from: https://europepmc.org/article/med/25355641

24. Shiny A, Bibin YS, Shanthirani CS, Regin BS, Anjana RM, Balasubramanyam M, et al. Association of neutrophil-lymphocyte ratio with glucose intolerance: an indicator of systemic inflammation in patients with type 2 diabetes. Diabetes Technol Ther. 2014 Aug;16(8):52430 .

25. Sefil F, Ulutas KT, Dokuyucu R, Sumbul AT, Yengil E, Yagiz AE, et al. Investigation of neutrophil lymphocyte ratio and blood glucose regulation in patients with type 2 diabetes mellitus. J Int Med Res. 2014 Apr;42(2):581-8.

26. Guo X, Zhang S, Zhang Q, Liu L, Wu H, Du H, et al. Neutrophil:lymphocyte ratio is positively related to type 2 diabetes in a large-scale adult population: a Tianjin Chronic Low-Grade Systemic Inflammation and Health cohort study. Eur J Endocrinol. 2015 Aug;173(2):21725 .

27. Lou M, Luo P, Tang R, Peng Y, Yu S, Huang $\mathrm{W}$, et al. Relationship between neutrophil-lymphocyte ratio and insulin resistance in newly diagnosed type 2 diabetes mellitus patients. BMC Endocr Disord. 2015 Mar 2;15:9.

28. Clinical Characteristics of Diabetic Patients with COVID-19 [Internet]. [cited 2021 Jun 18]. Available from: https://www.hindawi.com/journals/ jdr/2020/1652403/

29. Ji P, Zhu J, Zhong Z, Li H, Pang J, Li B, et al. Association of elevated inflammatory markers and severe COVID-19: A meta-analysis. Medicine (Baltimore). 2020 Nov 20;99(47):e23315.

30. Yang X, Yu Y, Xu J, Shu H, Xia J, Liu H, et al. Clinical course and outcomes of critically ill patients with SARS-CoV-2 pneumonia in Wuhan, China: a 
single-centered, retrospective, observational study. Lancet Respir Med. 2020 May;8(5):475-81.

31. Du R-H, Liu L-M, Yin W, Wang W, Guan L-L, Yuan M-L, et al. Hospitalization and Critical Care of 109 Decedents with COVID-19 Pneumonia in Wuhan, China. Ann Am Thorac Soc. 2020 Jul;17(7):839-46.

32. Yang J, Zheng Y, Gou X, Pu K, Chen Z, Guo Q, et al. Prevalence of comorbidities and its effects in patients infected with SARS-CoV-2: a systematic review and meta-analysis. Int J Infect Dis IJID Off Publ Int Soc Infect Dis. 2020 May;94:91-5.

33. JCI Insight - Comorbid diabetes results in immune dysregulation and enhanced disease severity following MERS-CoV infection [Internet]. [cited 2021 Jun 21]. Available from: https://insight.jci. org/articles/view/131774

34. Diabetes is a risk factor for the progression and prognosis of COVID-19 - Guo - 2020 - Diabetes/ Metabolism Research and Reviews - Wiley Online Library [Internet]. [cited 2021 Jun 21].
35. PRIME PubMed | Mean HbA1c, HbA1c variability, and mortality in people with diabetes aged 70 years and older: a retrospective cohort study [Internet]. [cited 2021 Jun 21]. Available from:https://www.unboundmedicine.com/ medline/citation/29674135/Mean_HbA1c_ HbA1c_variability_and_mortality_in_people_ with_diabetes_aged_70_years_and_older:_a_ retrospective_cohort_study_

36. Lim S, Bae JH, Kwon H-S, Nauck MA. COVID-19 and diabetes mellitus: from pathophysiology to clinical management. Nat Rev Endocrinol. 2021 Jan;17(1):11-30.

37. Mehta N, Kalra A, Nowacki AS, Anjewierden S, Han Z, Bhat $\mathrm{P}$, et al. Association of Use of AngiotensinConverting Enzyme Inhibitors and Angiotensin II Receptor Blockers With Testing Positive for Coronavirus Disease 2019 (COVID-19). JAMA Cardiol [Internet]. 2020 May 5 [cited 2021 Jun 21]; 